\title{
Difficulties in Establishing Liability in Online Defamation; Tanzania Experience
}

\author{
Charles W. Marwa \\ Correspondence: Charles W. Marwa, Assistant Lecturer, Faculty of Law Mzumbe University (LL.B-Mzumbe), LL.M \\ International Laws (MU), Legal consultant in Commercial and private law.
}

Received: February 22, 2018 Accepted: June 5, 2018 Online Published: June 11, 2018

doi:10.11114/ijlpa.v1i1.3356 URL: http://dx.doi.org/10.11114/ijlpa.v1i1.3356

\begin{abstract}
This paper is devoted to uncover difficulties in establishing liability in online defamation in Tanzania. The focus is on the effectiveness of the current laws and regulations relating to online defamation; and the lack of awareness on the part of the general public on legal and practical challenges in establishing liability over defamatory comments occurring on the internet.

The investigator discovered that, the existing legal framework in Tanzania cover issues of establishing liability in online defamation suffers from a number of inadequacies. Moreover the legal and practical challenges includes, the weakness of some law and regulations covering online defamation, limitation periods, jurisdiction and choice of law issues, investigation and admissibility of electronic evidence and its authenticity, identifying anonymous defendant and the rights to privacy. The author recommends that the government has to consider amending its law by taking on board the forgotten stakeholders opinions that would address by dealing with specific issues of liability in online defamation to internet users, Internet Service providers(ISP's) and intermediary for their defamatory comments.
\end{abstract}

Keywords: Liability, online defamation

\section{Introduction}

The law of defamation developed historically as a means of protecting reputations. It does so by providing a party with a means of redress in the event that their reputation is unfairly damaged by a third party. These legal protections have become increasingly important in today's digital age. The internet is now more accessible than ever before, and its interactive nature makes it easy for anyone to write messages or post content online. While this increased, the ability to share information has provided society with many benefits; it has also introduced increased risks. It is a medium which does not respect geographical boundaries. Concomitant with the utopian possibility of creating virtual communities, enabling aspects of identity to be explored, and heralding a new and global age of free speech and democracy, the Internet is potentially a medium of virtually limitless international defamation. ${ }^{2}$ Like other countries in the world Tanzania also has adopted the use of Information Communication Technology and the users face the problem of identifying a defendant in online when defamed. However there is no specific law which takes into account the development of technology that is always fast moving .

\section{Concept of Defamation and Online Defamation}

Defamation $^{3}$ is defined as "an intentional false communication either published or publicly spoken, that injures another's reputation or good name",. Defamation includes the common law torts of libel (involving written or printed statements) and slander (involving oral statements). Significantly both libel as well as slander could be committed via Internet medium. 5

On the Internet, defamation occurs where a person sends another person an email message containing defamatory remarks about another (natural or juristic) person (or its products).

\footnotetext{
${ }^{1}$ Rakochey R. and Dixon, M (2011) “The Law of Internet Defamation in Canada” Paper presented on March 3-4, 2011at Calgary, Alberta

${ }^{2} \mathrm{M}$, Collins, The Law of Defamation and the Internet, Oxford University Press, (2001). p. 24.02

${ }^{3}$ Garner B, (1990) Black's Law Dictionary, $6{ }^{\text {th }}$ Edition p. 449

${ }^{4}$ Skolnick, for example, maintains that: "The protection defamation law affords is to the individual's projection of self in a society." Jerome $\mathrm{H}$

Skolnick, "The Sociological Tort of Defamation" (1986) 74 California Law Review at 677

${ }^{5}$ Ibid
} 
Defamation rules are mainly based on case law and are supplemented by statutory law. In Tanzania the laws include, The Media Services Act 2016, The Cybercrimes Act 2015 and The Access of Information Act 2016. Such rules in relation to social media and publication on the internet are the same as for any other publication. However, publication on the internet does give rise to a number of difficulties in practice such as: many people say things online which they would not otherwise say, determining the place of publication, and whether Tanzanian courts have jurisdiction and what law applies, identification of publisher(s), wide dissemination of content,whether publisher is liable in a linked site and whether a search engine, such as Google, is liable for the publication of results which it generates.

\section{DEFAMATION AND SOCIAL MEDIA}

Defamation actions in relation to social media allegations of an extreme nature, generally without any basis and driven not by mere malice but some kind of internet 'road rage', are increasingly common before the courts... The anonymity instantaneous and wide-ranging reach of the Internet and social media make it a dangerous tool in the hands of person who see themselves as caped crusaders or whistleblowers, or alternatively want to 'troll' other members of the community for the purpose of gratifying their own wishes or fears or for the purpose of gaining attention" Justice Gibson

In the case of Hamisi v. Akilimali $^{6}$ defamation was defined by the court as communication to the mind of another, matters which are untrue and likely in the natural cause of things substantively to disparage the reputation of a third person. Form the definition, it could be argued that defamation as such requires the following ingredients to be proved; there should publication of a statement, the word must be false and those untrue statements must cause harm to the reputation of the plaintiff.

Defamation is an intrinsically personal wrong. The gist of defamation is actual or presumed damage to reputation flowing from publication. In other words, defamation flowing from publication (or communication) of information, ${ }^{7}$ in traditional libel cases publication is referred ${ }^{8}$ to as; "the date on which the libelous work was placed on sale or became generally available to the public." As such it has the following ingredients:

i. Publication of a statement,

ii. Statement makes reference to the plaintiff,

iii. Statement is communicated to some person or persons other than the plaintiff,

iv. Statement reaches the plaintiff, and

v. Statement causes actual or presumed damage to the plaintiff.

The question is, does one encounter similar 'ingredients' when defamation occurs in internet medium? The only difference is that the tort of defamation occurs when the defamatory imputation is published in electronic form, everything else remain the same. ${ }^{9}$

\section{SPECIAL CONSIDERATION IN KEY ELEMENTS}

Libel or Slander: Libel concerns publication of defamatory remarks in writing or some other permanent form While Slander-if defamatory remarks are spoken or in some sort of other transient form. It is generally settled that defamatory statements made on the internet are to be regarded as libel except for chat on an internet bulletin board which has been classified by courts as more akin to slander than libel ${ }^{10}$.

Emoticons: In the context of postings made via social media sites, individuals can express themselves in different ways, such as by posting funny pictures or using emoticons in addition to the text that they post. In McAlpine v Bercow(supra), the court held that a tweet suffixed with an emoticon could be defamatory.

Timing of Publication: In Flood v Times Newspaper Ltd ${ }^{l 1}$ The court ruled on the meaning of the newspaper article in a website publication, which the claimant alleged was defamatory when it was read after 5 September 2007, when the defendant knew that the comments were defamatory as the investigations giving rise to the speculation surrounding Mr. Flood had been dropped.The court agreed with the claimant that the words would be read by readers not only about events as they were on 2 June 2006, the date at the head of the article, but also events up to the date at which it was being read.

\footnotetext{
6 (1971) HCD 111

${ }^{7}$ V, Sharma, Information Technology Law and Practice, $2^{\text {nd }}$ Ed. Universal Law Publishing Co. Pvt Ltd New Delhi, (2010) p.306

${ }^{8}$ Kenneth Love v. William Morrow \& Co., (1993) A.D.2d 586

${ }^{9}$ V,Sharma supra note 7

${ }^{10}$ Nigel Smith v ADVFN Plc and others[2008] EWHC 1797(QB).

11 [2013] EWHC 2182(QB), 25 July 2013.
} 
Publication: In Hyperlinks that includes emoticons, additional text or hashtag, all these in principle, when in a tweet or post that offers a link to a defamatory publication could therefore fall within the definition of publication. ${ }^{12}$ Further that, in Metropolitan International Schools Ldt v Designtechnica Corporation and others ${ }^{13}$ It was held that, Google Inc was held not to be a publisher of a defamatory statement that could be located through a keyword search (for keywords relating to a defamatory statement) of its search engine. The High Court stated that Google had no control over deciding the search terms that were input by the search engine users or provided the content in any meaningful sense.

In addition, as per Bryce v Barber ${ }^{14}$, facebook rape formed defamation claim with the posting "Ray, you like kids and you are gay so I bet you love this picture, $\mathrm{Ha}$ ha" Individuals who access the accounts of others to post mischievous postings known as "Facebook rape" may be held responsible for defamation.

In Publication, The Repetitition Rule insists a person who repeats a defamatory allegation made by another is treated as if he had made the allegation himself. This is the position in Safaricom v Porting Access Kenya Limited ${ }^{15}$, Hence, sharing, re-tweeting may amount to re- publication.

In relation to Liability of ISPs: Whether an ISP is liable for defamatory remarks made by thirdy party or whether it is under legal obligation to disclose to the victim the personal identification information of the person who posted the defamatory comments. These questions have been addressed by The Cybercrimes Act 2015 in S.39-46, The Media Services Act 2016 S. 32, 33, 34, 38 \& 47 and The Cybercrimes Act 2015 S.16.

\section{ONLINE DFMATION: PUBLICATION AND REPUBLICATION}

Publication is defined as the action of making publicly known. In the context of internet, the term publication includes dissemination, transmission and storage of information in retrievable magnetic or optical storage like floppy disc, CDs, DVDs and etc. 16

It is known that publication in online forum or via sms or mms would qualify as publication for the law of defamation. In other instances like live (and unrecorded) webcast or other live digital broadcasts such as internet radio transmissions, the publication would be of the nature to raise an action in libel rather than slander. ${ }^{17}$ The major issue raised by digital distribution of defamatory material is the method of distribution and what this means for publication and republication.

However, the standard by court in taking jurisdiction over a defamation action is that of ${ }^{18}$ lexi loci delicti. This means that wherever a claimant suffers a loss or harm to his reputation and action may be raised. Traditional media outlets (defined or specific markets where they would distribute their contents) could take steps to limit their overseas actions. By targeting their publications or broadcasts to specific jurisdiction they could avoid extraterritorial actions as they would be in a position to establish that as publication took place only within a specific jurisdiction harm could not have occurred outwith that jurisdiction. This principle would defend publishers and broadcasters even if a few copies of the defamatory materials crossed borders in the bags or suitcase of travelers between states.

As illustrated in Berezovsky v Forbes, once the publisher or broadcaster actively distributes his product in other states he runs the risk of facing a libel action in any state in which he markets his product. The online distribute distribution modal is quite different. A static or dynamic digital space (web page, user generated content site, bulletin board, or broadcast site) is stored and updated via a server. That server may then be accessed anywhere in the world, and at any time unless access to sever is blocked. Digital communications cross borders without challenge and may be stored and recovered anytime. The effect of this, when faced with the challenges raised by the law of defamation, is though potentially paralyzing. Whereas previously publishers or broadcasters could choose to extend the audience for their publication by entering a new market or jurisdiction depending on whether it is viewed as a commercial or legal development, the suggested implication of digital publishing is that any publisher, no matter how small their intended audience may be, could potentially be seen to publish simultaneously in every country worldwide where their content could be read, and even more potentially damaging: Applying the principle in Berezovsky, every time their content was accessed by any user worldwide it would count for defamation law purposes as a publication of that content in the place where the user accessed it.

\footnotetext{
${ }^{12}$ Hird $v$ Wood [1894] 38 SJ 234

${ }^{13}$ [2009] EWHC 1765(QB)

${ }^{14}$ Unreported July 26[2010](HC)

${ }^{15}$ Civil Case 167 of 2011

${ }^{16}$ http://www.unswlawjournal.unsw.edu.au/sites/default/files/turner_371.pdf accessed on 15/05/2016

17 Defamation Act of 1952 (UK)

${ }^{18}$ See Berezovsky v Forbes Inc.(No.1) [2000] 1 WLR;2000 WI 544123
} 


\section{ONLINE DEFAMATION AND THE'de minimis'RULE}

In Dow Jones, Inc.v Jameel, ${ }^{19}$ Mr Justice Eady found in favour of the plaintiff by stating that...

'It will be an abuse of process to continue to commit the resources of the English court, including substantial judge and possibly jury time, to an action where so little is now seen to be at stake. Normally where a small claim is brought, it will be dealt with by a proportionate small claims procedure. Such a course is not available in an action for defamation where, although the claim is small, the issues are complex and subject to special procedure under the Civil Procedure Rules.'

The Jameel case adds greatly to our understanding of the tort of defamation in the online environment. We can now see that although a single publication within the jurisdiction of the courts may be enough to allow them to take jurisdiction, it is for the plaintiff to establish they have suffered substantial harm, that is harm substantial enough to overcome the 'de minimis' rule: Failure to establish that, may lead to your case being thrown out as an abuse of legal process.

In order to get the relationship between defamation and publication on the internet medium, it is necessary to understand: when a publication takes place, how a publication takes place, where does publication takes place and who is responsible for the publication of the defamatory statements.

\section{A. When a Publication Takes Place, (Which Involves Time of Occurrence)}

Publication occurs where oral or written statements are seen or heard and comprehended by the reader or hearer. ${ }^{20}$ From this point of view, the process of publication is complete when the communication reaches him. In the common law case of Godfrey v. Demon Internet ltd. ${ }^{21}$, Morland, J. ruled that;

... publication occurs where the defendant transmits and whenever there is transmitted from storage of its new server a defamatory posting, publishing that post to any subscriber to its ISP who accesses the newsgroup containing that posting. Thus every time one of the defendant's customers accesses "soc.culture.thai" and sees that posting defame the plaintiff, there is publication to that customer."

\section{B. How a Publication Takes Place, (which Involves the Mode of Publication)}

The issue concerning what form (mode) publication has happened is an important issue in the techno-legal driven environment, it looks into the mode of publication; it can be audio, video, textual or multimedia. ${ }^{22}$ Instances of defamation in electronic form include generating, sending or receiving defamatory e-mails, online bulletin board messages, chat room messages, music downloads, audio files, one-to-one email message, mailing lists, newsgroup and World Wide Web (Potential sites for defamation) on the internet as explained hereunder;

\section{One to One E-mail Messages}

As anyone who has used email will know, it is remarkably quick and easy to use. Comments can be typed in haste and sent at the press of a button. Compared to conventional written correspondence, where there is typically time to draft the statement, print or type it out, re-read, re-draft, and then think before signing, putting the message in an envelope, attaching a stamp and putting in the post, transmission of email is virtually instantaneous and usually, once sent, is irrevocable. As a result, email correspondence is often in substance more like spoken conversation than written interaction for habitual users hasty, ungrammatical and language tends to lead parties to say things they would not commit to writing, but would often not say when interacting with the other party.

Furthermore, psychologically, electronic interaction combines a sort of deceptive distance. One is after all sitting safe behind a terminal in one's own office when writing with a kind of equally deceptive intimacy. Studies and anecdotal evidence show that there is lack of body language, eye contact or spoken cues, as there would be in conversation or on the phone, to prevent the making of inappropriate statements. All this means that, those sending email are dangerously prone to making remarks that turn out to be legally actionable. ${ }^{23}$

In Tanzania, The case of Lazaraus Mirisho Mafie and M/S Shidolya Tours \& Safaris v. Odilo Gasper Kilenga Alias

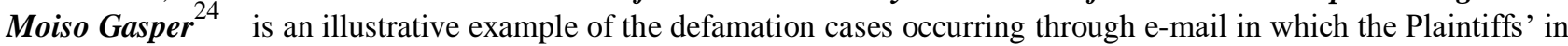
this case claimed against the Defendant for certain sums of money as special and general damages resulting from the

\footnotetext{
${ }^{19}$ [2005] EWCA Civ 75;[2005]Q.B946

${ }^{20}$ Mark, P. Carolyn, P. and Peter, W. (2003) "The cyber boundaries of reputation: implications of the Australian High Court's Gutnick decision for journalists." http://epublications.bond.edu.au/hss_pubs/79 accessed 26/03/2013

${ }^{21} 4$ All ER 342 High Court

${ }^{22} \mathrm{~V}$, Sharma, supra note 7

${ }^{23} \mathrm{E}, \mathrm{Lilian}$ 'Law and the Internet - Regulating Cyberspace' Defamation and the Internet: Name Calling in Cyberspace, Hart Publishing, London, (1997),See also www.law.ed.ac.uk accessed on 11/05/2016

${ }^{24}$ Commercial Case No. 10 of 2008, The High Court of Tanzania at Arusha (unreported)
} 
alleged defamatory e-mail statement which the plaintiffs claim was sent, made and published by the Defendant against him.

\section{Mailing Lists}

The format of an electronic mailing list involves various parties subscribing by email to the list, which is administered by a central host. ${ }^{25}$ The subject of discussion of the list may be anything from Internet law or other topics. Usually, the list is set up so that, by default, any email message sent by any one subscriber to the list is "bounced" or "exploded out" to every other subscribers many of whom will, as the parlance goes, "lurk" and never be known to exist to the person commenting. Mailing lists combine all the general problems of email discussed above, with some extra difficulties of their own. It is very easy for the slightly careless or inexperienced user of such a list to think they are replying only to the maker of a particular comment but actually send their reply to every member of the list.

The embarrassment happens, particularly where the members of the list form a small professional community within which the professional reputation of the person defamed can be severely damaged. ${ }^{26}$ It is not a coincidence that one of the very few cases across the globe on Internet libel has not been settled out of court, In Rindos $v$ Hardwick ${ }^{27}$ revolved around comments made on a mailing list for academic anthropologists in which comments were made implying that Rindos, the Australian plaintiff, had been denied tenure because he was not a properly ethical researcher and was academically incompetent.

\section{E. Newsgroups, the USENET and Discussion Forum}

Newsgroups are discussion forum which are made up of comments from their subscribers, sorted by subject matter. Subscribers post comments to a newsgroup which seems to be a rudimentary software, obtainable for free as shareware with internet connection. Collectively, the newsgroups available to Internet users are sometimes known as the "Usenet". There is something like 14,000 Usenet newsgroups subscribed to en masse by millions of subscribers, located in every country where there is Internet access. As a result, any comment posted to a Usenet newsgroup is virtually guaranteed to be published, and read, within days if not hours, in many hundreds of national jurisdictions. As can be imagined, the volume of material published in these forums is enormous one estimate is that around four million articles are available at any particular time. ${ }^{28}$

Newsgroups are even more problematic from the defamation point of view than the rest of the Internet because of what may be described as traditional "Internet culture". Until very recently, roughly, the early 2000's, Internet was largely the domain of technophiles, students, academics and workers in the computer industry. These users largely accessed the Internet for free and used it for non-commercial purposes. There was a strong collective sentiment towards anarchy, libertarianism and free speech rights and a strong corresponding dislike of corporate, governmental or legal authority or control.

In this culture, full, frank and unfettered discussion known as "flaming", which was often indistinguishable from rudeness and abuse, was not only tolerated but largely encouraged. The usual remedy for being flamed was not to post a writ for libel, but extra-legal self help in other words, flame back. It was and is not uncommon for newsgroups to degenerate into "flame wars" torrents of abusive comments which destroy all sensible discussion in the group. This was well, perhaps, when most Internet users shared a similar cultural background. But in recent years the Internet has ceased to be the domain of "netizens" and become extensively used by individuals and families, including children, who pay for Internet access and expect it to respect the same standards of decency and courtesy as other media.

More importantly, corporate use has expanded enormously, as firms who see the Internet as a domain for commercial expansion establish their own connections and Web sites. For these users, flaming and abuse are not acceptable. Self help remedies, and preservation of corporate reputation is paramount. ${ }^{29}$ In Tanzania there is 'Jamii forums' where members post and others comment depending on the type of the topic. Another blog called Ze Utamu was also shut down with the help of international law enforcing agencies, when it was found to be invading the privacy of individuals. 30

\section{F. $\quad$ The World Wide Web}

\footnotetext{
${ }^{25}$ E,Lilian 'Law and the Internet - Regulating Cyberspace' Defamation and the Internet: Name Calling in Cyberspace, Hart Publishing, London,(1997) See also www.law.ed.ac.uk accessed on 12/05/2016

${ }^{26}$ Ibid

${ }^{27}$ Australian Supreme Court No 993 of 1994

${ }^{28} \mathrm{E}$, Lilian supra note 13

${ }^{29}$ Ibid

${ }^{30}$ Media Council of Tanzania (2010) “State of the Media Report” Final: Layout 1 5/6/11 3:49 PM p.37 see also www.mct.or.tz/.../index.php?option accessed on 15/05/2016
} 
The Web is now so large, and increasing in size so fast that it is impossible even to pin down estimates of its size. ${ }^{31}$ Like newsgroups, Web sites can be accessed and read in multiple jurisdictions, and they therefore share many of the problems of transnational publication discussed above. But perhaps the major unique problem with the Web is how far it allows any individual to mimic traditional publishing at very low cost. "Home pages" can be set up which do a good job of looking like electronic journals or glossy magazines and which can be extremely attractive, with good design and graphic content.

However, many of the parties setting up Web sites often fans of popular music or TV programmers, students, pressure groups, or amateur associations are not already traditional publishers, have no knowledge of the law of defamation or libel, and may well find themselves publishing defamatory statements without fully appreciating their potential liability. ${ }^{33}$ For instance, the then President of the United Republic of Tanzania, Dr. Jakaya Mrisho Kikwete, was once the victim of cyber defamation, when one of the websites named 'Ze Utamu', published defamatory pictures involving him. 34

\section{G. Where the Publication Takes Place (which Involve Issues of Jurisdiction)}

The issue of whether the publication has occurred is not easy to define as a defamatory statement can be published anywhere in the world, where there is access to internet. In the context of internet, it is not necessary for the plaintiff in all cases to prove directly that the defamatory statement was brought to the actual knowledge of anyone, person(s) other than the plaintiff himself. ${ }^{35}$ Publication is only established if the plaintiff makes reasonable inference that the publication was accessible in the said jurisdiction. ${ }^{36}$ In contrast, with the internet it is not all probable that, every website will be accessed in every jurisdiction where it can theoretically be accessed. ${ }^{37}$ So as a matter of reasonable inference, it can be assumed that any site put on the internet and accessible from anywhere is in fact accessed everywhere. $^{38}$

In $\boldsymbol{R}$ v. Graham Waddon, ${ }^{39}$ the defendant submitted that, because the internet publication had necessarily occurred abroad, therefore the instant court did not have jurisdiction. Hardy Christopher, J. held:

"Publishing an article under s. 1(3), (b) of the 1959 Act included data stored electronically and transmitted. To transmit simply meant to send from one place to another. In the instant case, an act of publication took place when the data was transmitted by the defendant or his agent to the service provider, and the publication or transmission was in effect still taking place when the data was received. Both the sending and receiving took place within the jurisdiction of the court and it was irrelevant that the transmission may have left the jurisdiction in between the sending and receiving".

In other words, the court exercised its jurisdiction, even when the pornographic material was held on a US based server. The court's argument has been that, since the material was uploaded (by Waddon) and downloaded (by the police) in the UK, it could be classified as being "published" in the UK.

Also in another case of Joseph Gutnick v. Dow Jones \& Company Inc ${ }^{40}$ Justice Hedigan held that, the 'publication' of an online article occurred in the jurisdiction where the article was downloaded, regardless of where it was uploaded or where the publisher's server resided.

The aforesaid judgment has made it clear, that a person is defamed at a place where publication is made, and the context of internet, it is the downloading of the information that is a relevant fact for identifying the jurisdiction. The criticism that the plaintiffs may resort to "forum shopping" in order to bring their claim in a jurisdiction which provides them with a greater chance of success is untenable. Before deciding any case, the courts will have to ascertain whether there

\footnotetext{
31 Scotland on Sunday, 26 May 1996. See, www.law.ed.ac.uk accessed on 10/04/2013

32 Financial Times, June 51997

33 See also the issue of www.zeutamu.blogspot.com which later on the website was banned.

${ }^{34}$ In the case, Ferdinand Charles Urio, a teacher at Uomboni Secondary School in Marangu, charged, alongside Daniel Robin, for publishing indecent pictures of the Head of State on the internet. Available at http://bongoline.com/news/1929/JK+defamation/ruling+date=set

35 , V, Sharma (2010) Op Cit p.308

36 Ibid

37 Ibid

${ }^{38}$ Kohl, U. "Defamation on the internet- a duty free zone after all?", Sydney L. Rev. 119, (2000) pp.126-127

39 Southwark [Crown Court, 30/6/1999].

40 [2001] VSC 305
} 
exists a substantial connection with the place where proceedings are instituted. ${ }^{41}$

\section{H. Liability for Online Defamation}

The issue of liability is another important issue to be determined in relation to defamation. There is no doubt that, the poster of a defamatory comment will incur liability. ${ }^{42}$ Another kind of liability is employer's liability, more companies make use of email as a method of communication between staff, so there will be increasing exposure to action on the basis of vicarious liability in respect of the use or misuse made of the communication network. ${ }^{43}$ Again, ISP as the operator of an online service incur liabilities in certain circumstances, however there is more controversy as to whether ISP should incur liabilities akin to those traditional publishers in respect of messages appearing on their system. ${ }^{44}$

Again, publication of criminal defamation creates a criminal offence, which is normally a civil wrong in which damages are paid to repair the reputational damage suffered by the defamed person. ${ }^{45}$

\section{Legal Framework Governing Online Defamation in Tanzania}

\section{A. The Constitution of the United Republic of Tanzania, 1977}

The Constitution of the United Republic of Tanzania, $1977^{46}$ prohibits any interference with any personal communications whether through media or not. Every person is free to communicate and to receive any information but the freedom is not absolute, it is limited as whoever communicates must ensure that, he does not injure others reputation.

\section{B. The Newspapers Act $t^{47}$}

The Newspapers Act, especially PART VI of the Act, provides the meaning of libel in defamation. The Act stated that any person who, by print, writing, printing, effigy or by any means otherwise than solely by gestures, spoken words or other sounds, unlawfully publishes any defamatory matter concerning another person, with intent to defame that other person, shall be liable of the offence of defamation.

It further provides the element of defamation, when a person is defamed required to prove that, there is a defamatory matter is that likely to injure the reputation of any person by exposing him to hatred, contempt or ridicule, or likely to cause damage to any person in his profession or trade by an injury to his reputation. ${ }^{49}$

There should also be publication, ${ }^{50}$ A person publishes a libel if he causes the print, writing, painting, effigy or other means by which the defamatory matter is conveyed, to be dealt with, either by exhibition, reading, recitation, description, delivery or otherwise, so that the defamatory meaning thereof becomes known or is likely to become known to either the person defamed or any other person.

It is not necessary in a case of libel that, the defamatory meaning should be directly or completely expressed; it suffices if such meaning and its application to the person alleged to be defamed can be collected either from the alleged libel itself or from any extrinsic circumstances or partly from the one and partly from the other means.

\section{The Electronic and Postal Communication Act, $\mathbf{2 0 1 0}^{51}$}

The Act empowers the Minister and the Tanzania Communication Regulatory Authority ${ }^{52}$ to enact Regulations to regulate content related matters as provided under section 103 of the Act. The Act also provides for establishment of code of conduct under section $104^{53}$ which, inter alia deal with offensive materials disseminated through the internet. The code and regulations may settle the position in Tanzania in respect of defamatory materials in the following areas.

(i) Be binding on all Content Service Licensees;

\footnotetext{
${ }^{41}$ Sharma, V. (2010) Op Cit p.306

${ }^{42}$ Lloyd, I. (2008) Op Cit p. 574

${ }^{43}$ Lloyd, I. (2008) Op Cit p. 574

${ }^{44}$ www.legalservicesindia.com/articles/defcy.htm accessed on 13/05/2016

${ }^{45}$ MEDIA LAW HANDBOOK FOR SOUTHERN AFRICA - VOLUME 2 p. 585

${ }^{46}$ The Constitution of the United Republic of Tanzania [CAP. 2 R.E. 2002]

${ }^{47}$ The Newspapers Act [CAP 229 R.E. 2002]

${ }^{48}$ see section 38

49 see section 39

${ }^{50}$ Section 40 of The Newspapers Act [CAP 229 R.E. 2002]

51 Tanzania Communication Regulatory Authority, Act No. 3 of 2010

${ }^{52}$ This is the Act which regulates all communication activities in Tanzania including broadcasting and online communications

${ }^{53}$ Section 104 of The Tanzania Communication Regulatory Authority, Act No. 3 of 2010
} 
(ii) Prohibit the provision of content which is indecent, obscene, false, menacing or otherwise offensive in character. $^{54}$

\section{The Media Services Act 2016}

In part VII of the Act deals in extenso with defamation and libel, with many sections having

been lifted from the Newspaper Act 1976. Although sections 187 to 194 of the Penal Code on defamation were repealed, thus decriminalizing defamation, the Act still speaks of "punishment" in section 32 (1) which deals with "privileged" cases of defamation. 55

The proposed Media Service Act 2016, is also silent when it comes to defamation that arise out of social media (Cyber defamation). Part VII of the Act from section 29 to 35 provides for defamation provisions. The Act provided this part of provision simply because this law will repeal the Newspaper Act which previous used to provide for defamation.

In general, civil defamation legislation must be applicable to all persons and organizations and not the media alone. Media practitioners are citizens like all others and must be treated equally. Clauses on civil defamation should thus be part of the general law and not a Media Services Act. The Act provides for redress for defamation by saying in section 35 that a person who "alleges that a print or electronic media content is defamatory within the meaning of this Act, that person may make (a) complaint to the Board for redress". The Board as a government controlled organ is not the appropriate body for adjudication in such matters. The Declaration of Principles on Freedom of Expression in Africa says in its article IX (2): Any regulatory body established to hear complaints about media content, including Media Councils, shall be protected against political, economic or any other undue interference. Its powers shall be administrative in nature and it shall not seek to usurp the role of the courts.

Article XII of the Declaration require States to ensure that their laws relating to defamation conform to the following standards.

(i) No one shall be found liable for true statements, opinions or statements regarding public

figures which it was reasonable to make in the circumstances;

(ii) Public figures shall be required to tolerate a greater degree of criticism; and sanctions shall never be so severe as to inhibit the right to freedom of expression, including by others.

(iii) Privacy laws shall not inhibit the dissemination of information of public interest.

Instead, as outlined above, the Act even empowers the board to strike a journalist from the roll of accredited journalists for "gross professional misconduct".

Therefore, the Act is not in tandem with the international instruments to which Tanzania is a signatory. Hence, a failure to abide by international obligations.

E. The Cybercrime Act 2015

Section 16 of the Act is used as a safeguard provision for defamatory statement arising out of internet usage and social media. The section criminalizes publication of false information through internet or social media.

Any person who publishes information, data or facts presented in a picture, text, symbol or any other form in a computer system where such information, data or fact is false, deceptive, misleading or inaccurate and with intent to defame threaten, abuse, insult, or otherwise deceive or mislead the public or counseling the commission of an offence, commits an offence, and shall on conviction be liable to a fine not less than five million shillings or to imprisonment for a term not less than three years or to both. For that provision above, it is obviously that in Tanzania all defamatory statements arising out of social media or use of internet are criminal offences (criminal defamation).

Therefore one can articulate that, Tanzania is one of the countries which criminalize cyber defamation, instead of making it as civil defamation which is a recommendation of international law standard, freedom of expression principles. Criminal defamation can be one of the remedy and may help the person defamed, but compared to other jurisdictions and international law principles the remedy does not suffice. International bodies such as the UN and the Organization for Security and Co-operation in Europe (OSCE) have recognized the threat posed by criminal defamation laws and have recommended that they should be abolished. 56

Nevertheless, criminal remedy seems difficult to be enforceable in Tanzania, simply because a person who claims to be

\footnotetext{
${ }^{54}$ Ibid see section 104(1)

55 The Media Services Act 2016

${ }^{56}$ https://www.article19.org/pages/en/criminal-defamation.html accessed on 15/05/2016
} 
defamed will have to channel his/her grievance though police force, and thereafter will be the duty of police force (cyber unit) to investigate, prosecute the person who published the false information with defamatory element.

\section{Recommendations with Respect to Online Defamation}

It has been shown that Tanzania faces challenges in combating online defamation and other related cyber crimes. The following recommendations will help to deal with challenges to online defamation in Tanzania.

a. Since the existing laws and regulations in Tanzania have not taken on board some vital stakeholders comments during the process of their formation , therefore effective measures should be taken to revisit the laws that will sufficiently cover and address how liability should be established to users, ISPs, intermediary for online defamation.

b. Tanzania should enact specific law to deal with online Defamation instead of incorporating such law in another law that cater for other matters. The enacted law should address how internet user will be protected in from online defamation, and how and when the internet users, ISP's and intermediary may face liability when they make, facilitate, transmit defamatory comment in online environment.

c. There is a need of establishing special machinery charged with the duty of identifying the anonymous defamers in online communications. The available procedure in Tanzania is very cumbersome and raises a lot of complexity especially when the internet used for defamatory is a public one (cybercafés). The National CERT should be introduced to the public so that, the public could be aware of how this machinery could help them because the whole population isn't aware of its role

d. The author recommends to the government that since the Act is going to be tabled again in the parliament this year, therefore it is an opportunity for the new provision to be enacted in the Media Services Act to cover Cyber defamation, and this should reflect the newly issued declaration of freedom of expression and internet of 2011. This is possible because as narrated above the Electronic and Postal Communication Act (EPOCA) gives the mandate of control content of social media and internet to the Minister of Information, Youth, Sports and Culture therefore simply because the newly Act is under this Ministry this is the chance to enact the same.

e. The author recommends that, the new law to provide clear that, no provider or user of an interactive computer service shall be treated as the publisher or speaker of any information provided by another information content provider, for this case liabilities for cyber defamation will lie for publisher, and not services providers the same principle is used in India, UK, and US. Nevertheless, the government has to adopt procedures as those of UK, whereby if a person claims certain link, social media, or websites is having defamatory statement to contact the provider and ask for removal.

f. That, Tanzanian legislation should require public figures to tolerate a greater degree of criticism than ordinary citizens.

g. Under The Cybercrime Act, the procedure is time-consuming and unreliable to be followed by a person defamed, unreliable in the sense that not all the time Police will have capacity to make a follow-up of all cases arising out of cyber defamation with the number of internet user growing every day. In other jurisdiction cyber defamation law has developed in a great extent, whereby a person who has been defamed may rush to court to seeking for remedy of civil nature, or alternatively request the website provider or person who posted that information though social media to remove though formal procedure provided under their law or regulations.

\section{Conclusion}

Recent developments in ICT resulted into increased of freedom of expression, hence the growing participation in Internet chat rooms, one to one e-mail, mailing list, social networks and online forums which are likely to cause potential online defamation. As Internet users can easily create bogus profiles and make anonymous and unlimited defamatory postings regarding any person. Tanzania has used different legislations to deal with these challenges such as the Tanzania Communication Regulatory Authority Act, EPOCA, Evidence Act, Penal Code, Newspaper Act, Cybercrime Act, 2015 as well as the Media Services Act, 2016,

Despite the fact that, different legislations and initiatives have been taken to deal with problems posed by the internet, still online defamation poses a great threat to Tanzania and this has been due to different practical and legal challenges in establishing liability in online defamation.

Lastly it can be argued that, Tanzania laws are not exhaustive enough to cover the challenges brought by ICT revolution especially on holding internet user, ISPs, hackers and intermediary liable for defamatory statements occurring through online. 


\section{References}

\section{Statutes}

The Electronic and Postal Communication Act, 2010

The Newspapers Act [CAP 229 R.E. 2002]

Tanzania Communication Regulatory Authority, Act No. 3 of 2010

The Cybercrime Act No.14 of 2015

The Media Services Act 2016

\section{Books}

Collins M, The Law of Defamation and the Internet, Oxford University Press, (2001).

Sharma, V., Information Technology Law and Practice, $2^{\text {nd }}$ Ed. Universal Law Publishing Co. Pvt Ltd New Delhi, (2010)

\section{Case laws}

Godfrey v. Demon Internet ltd. (1999) 4 All ER 342

Hamisi v. Akilimali (1971) HCD 111

Kenneth Love v. William Morrow \& Co., (1993) A.D.

Lazaraus Mirisho Mafie and M/S Shidolya Tours \& Safaris v. Odilo Gasper Kilenga Alias Moiso Gasper; Commercial Case No. 10 of 2008, The High Court of Tanzania at Arusha (unreported)

Rindos v Hardwick ;Australian Supreme Court No 993 of 1994

\section{Articles}

Jerome H.S, 'The Sociological Tort of Defamation' California Law Review, vol. 74 (1986)

Kohl, U, 'Defamation on the internet- a duty free zone after all?', Sydney L. Rev. 119

\section{Reports}

Rakochey, R. (2011) “Master Defamation Paper in Canada” presented at Federal Press on

March 3-4

\section{Onlinesources}

http://www.onesbahamas.com

http://epublications.bond.edu.au/hss_pubs/79

www.law.ed.ac.uk

www.mct.or.tz/.../index.php?option

www.legalservicesindia.com/articles/defcy.htm

https://www.article19.org/pages/en/criminal-defamation.html

http://www.quotegarden.com/justice.html

http://bongoline.com/news/1929/JK+defamation/ruling+date=set

\section{Other references}

Garner B, (1990) Black's Law Dictionary, $6^{\text {th }}$ Edition

MEDIA LAW HANDBOOK FOR SOUTHERN AFRICA - VOLUME 2

\section{Copyrights}

Copyright for this article is retained by the author(s), with first publication rights granted to the journal.

This is an open-access article distributed under the terms and conditions of the Creative Commons Attribution License which permits unrestricted use, distribution, and reproduction in any medium, provided the original work is properly cited. 